\title{
Clinical and Laboratory Evaluation of Hyperlipemic and Hypothyroid Patients
}

\author{
Ana Valéria Barros de Castro, Alexandra Procópio Bononi, Flávio Aragon, Carlos Roberto Padovani, \\ Célia Regina Nogueira, Gláucia M. F. da Silva Mazeto, Walkyria de Paula Pimenta
}

Botucatu, SP - Brazil

\begin{abstract}
Objective - To determine the frequency of hypothyroidism in a sample of hyperlipemic patients and evaluate clinical and laboratory factors indicative of thyropathy among them.
\end{abstract}

Methods-Fifty-one hyperlipemic patients, grouped according to an earlier or recent diagnosis of their thyroid function into euthyroid and hypothyroid, were evaluated with clinical and laboratory examinations of blood levels of free $T_{4}$ and TSH (by radioimmunoassay). Patients were on average $46.8 \pm 11.7$ years old, predominantly of the female sex (62.5\%); 31\% had a previous diagnosis of hypothyroidism and were under treatment with thyroxin.

Results - Fourteen three percent of patients analyzed had hypothyroidism, which had not been detected before. Differentiating attributes of the groups analyzed were: a predominance offemales among the hypothyroid patients and a higher HDL serum concentration among those recently diagnosed.

Conclusion - In the present study, new cases of hypothyroidism in hyperlipemic patients were a frequent occurrence, yet few clinical and laboratory data except tests evaluating free $T_{4}$ and TSH in the blood indicated which patients had thyroid dysfunction.

Keywords: hypothyroidism, hyperlipemia, dyslipemia

School of Medicine of Botucatu - UNESP

Mailing address: Ana Valéria Barros de Castro - UNESP - Caixa Postal, 584 18618-970 - Botucatu, SP - Brazil
Hypothyroidism is a clinical syndrome resulting from a decrease in the thyroid hormones thyroxin $\left(\mathrm{T}_{4}\right)$ and triiodothyronine $\left(\mathrm{T}_{3}\right)$. It is classified as primary, secondary, or tertiary, according as to whether the cause of the disease is localized respectively in the thyroid, the hypophysis [resulting from thyroid stimulating hormone (thyrotrophin-TSH) deficiency], or the hypothalamus [resulting from TSH releasing hormone (TRH) deficiency]. In primary hypothyroidism a concomitant increase in thyrotrophin (TSH) occurs in an attempt to stimulate the thyroid gland to produce T4 and T3. In these cases, as long as healthy thyroid tissue is available, normalization of $\mathrm{T}_{4}$ will occur, characterizing a condition of subclinical hypothyroidism ${ }^{1}$.

Both subclinical and symptomatic hypothyroidism are associated with various risk factors for atherosclerotic disease, including systemic arterial hypertension, hypercholesterolemia, hypertriglyceridemia, increased lipoprotein $\mathrm{a}^{2}$, and endothelial dysfunction ${ }^{2,3}$.

The occurrence of 2.6 to $10 \%$ of cases of hypothyroidism traced to hyperlipemia including its subclinical form could only be detected in the laboratory by increases in TSH and normal $\mathrm{T}_{4}{ }^{4-6}$. Several studies suggest that hyperlipemic patients should be tested for the presence of hypothyroidism ${ }^{4-6}$. The objectives of the present work were to determine the frequency of hypothyroidism in patients seen at the dyslipemia outpatient clinic of the Clinics Hospital of the School of Medicine of Botucatu (HCFMB), to determine the frequency of the arrival of new cases of hypothyroidism in this clinic by analyzing patients' blood concentration of free $\mathrm{T}_{4}$ and TSH, and to classify hyperlipemic patients, clinically and in the laboratory, according to their functional thyroid condition.

\section{Methods}

Following exclusion of patients with disease conditions interfering with their lipid profile or thyroid function (diabetes mellitus and uremia) $)^{7-9} 51$ of 85 patients followed at the outpatient dyslipemia clinic of the HCFMB between 
1996 and 1998 had their blood analyzed for $T_{4}$ in its free, ie, nonprotein bound form $\left(\mathrm{FT}_{4}\right)$, and for TSH. Patients were on average $46.8 \pm 11.7$ years old and predominantly of the female sex $(62.5 \%)$. In this sample, 16 of the patients had a previous diagnosis of hypothyroidism (early group) and were under thyroxin treatment at the moment of evaluation. Cases detected during recent testing were considered new cases of thyroid dysfunction.

Hormone and biochemical estimations were performed by radioimmunoassay (CIS-BIO-France) and colorimetric enzyme assays (SERA-PAK-USA), respectively. Cholesterol contained in low-density lipoprotein (LDL-cholesterol) was calculated by Friedwald's formula ${ }^{8}$. Normal values of $\mathrm{FT}_{4}$ and of TSH were 0.8-2.0ng/dL and 0.25-4.0mIU/mL, respectively. Lipid blood concentrations were considered altered when total cholesterol was $\geq 240 \mathrm{mg} / \mathrm{dL}$; LDL-cholesterol was $\geq 160 \mathrm{mg} / \mathrm{dL}$; HDL-cholesterol (high-density lipoprotein) was $\leq 35 \mathrm{mg} / \mathrm{dL}$, and triglycerides were $\geq 200 \mathrm{mg} / \mathrm{dL}$. Altered hormone levels were confirmed upon repetition of the analyses.

Comparative analyses were performed according to the functional thyroid state. Goodman's test was employed for comparisons of the study groups to contrast between and within multinomial populations. To compare quantitative variables, analysis of variance or the Kruskal-Wallis tests were used according to the probabilistic distribution of the data. The chi-square test was used to compare frequencies, and data were correlated by Spearman's method. Values of $\mathrm{P}<0.05$ were considered statistically significant.

\section{Results}

The frequency of new cases of hypothyroidism in the present sample was $5 / 51$ patients $(9.8 \%)$. If previously diagnosed cases of the disease are excluded, of the 51 patients the frequency of new cases rose to $14.3 \%(5 / 53)$.

Of the new cases, 3 had subclinical primary hypothyroidism (normal $\mathrm{FT}_{4}$ increased TSH); one had biochemical or asymptomatic hypothyroidism (low $\mathrm{FT}_{4}$ high $\mathrm{TSH}$ ) and one had secondary hypothyroidism (low $\mathrm{FT}_{4}$, normal TSH).
In the group of early hypothyroid patients $(n=16), 44 \%$ were noncompensated $\left(\mathrm{FT}_{4}<0.8 \mathrm{ng} / \mathrm{mL}\right.$ or TSH $>4.0 \mathrm{mIU} / \mathrm{mL}$, or both) and $19 \%$ had iatrogenic hyperthyroidism (FT $>2.0 \mathrm{ng} / \mathrm{mL}$ or $\mathrm{TSH}<0.25 \mathrm{mIU} / \mathrm{mL}$, or both).

The waist/hips index $(\mathrm{W} / \mathrm{H})$ was increased in $57 \%$ of female $(\mathrm{W} / \mathrm{H}>0.8)$ and in $43 \%$ of male subjects $(\mathrm{W} / \mathrm{H}>1.0)$, $(\mathrm{P}<0.05)$. Among women, no difference existed in this index among groups; among men, however, the $\mathrm{W} / \mathrm{H}$ index was higher in the euthyroid group in relation to the group of early hypothyroid subjects.

In the overall sample, $76.4 \%$ of the women were in menopause. No difference in the frequency of this characteristic was noted between groups.

Further clinical characteristics of the patients studied are shown on Table I.

The most frequently encountered types of hyperlipemia of the patients were the mixed and the isolated hypercholesterolemic varieties (Figure 1). No differences in the frequencies regarding type of hyperlipemia were found between the groups.

As shown in Table II, with the exception of blood concentrations of HDL-cholesterol, which were higher in the group of new cases of hypothyroidism, we did not find differences between other lipid fractions, glycemia, or creatinine levels between groups. Serum concentrations of TSH were higher and $\mathrm{FT}_{4}$ was lower in the group of new cases of hypothyroidism.

No correlation existed between seriousness, type of hyperlipemia, and thyroid dysfunction.

\section{Discussion}

The frequency of hypothyroidism in the present sample $(14.3 \%)$ was higher than that found in the population in general (10-12\%) $)^{10,11}$ as well as that of hyperlipemic patients (2.6 to $10 \%)^{3-6}$. These discrepancies are probably due to sampling differences regarding number, sex, age, and origin of the patients ${ }^{4}$.

It has been suggested that thyropathy testing by blood analyses of total or free $\mathrm{T}_{4}$ or of $\mathrm{TSH}^{11}$ in populations in ge-

\begin{tabular}{|c|c|c|c|}
\hline \multirow[t]{2}{*}{$\begin{array}{l}\text { Group/ } \\
\text { Characteristics }\end{array}$} & \multicolumn{2}{|c|}{ Hypothyroidism } & \multirow{2}{*}{$\begin{array}{l}\text { Euthyroidism } \\
(\mathrm{n}=30)\end{array}$} \\
\hline & New cases $(n=5)$ & Earlier $(\%)(\mathrm{n}=16)$ & \\
\hline $\operatorname{Sex}(M: F)$ & $1: 1.5^{\mathrm{b}}$ & $1: 7^{\mathrm{b}}$ & $1: 0.7^{\mathrm{a}}$ \\
\hline Age (years) ${ }^{1}$ & $44.4 \pm 14.9$ & $53.7 \pm 9.7$ & $54.2 \pm 10.8$ \\
\hline Sedentarism $(\%)$ & 40.0 & 18.8 & 43.3 \\
\hline $\operatorname{BMI}\left(\mathrm{kg} / \mathrm{m}^{2}\right)^{1}$ & $28.1 \pm 2.7$ & $27.3 \pm 4.8$ & $26.9 \pm 4.9$ \\
\hline $\mathrm{W} / \mathrm{H}^{1}$ & $0.91 \pm 0.07$ & $0.92 \pm 0.2$ & $0.96 \pm 0.13$ \\
\hline Smoking (\%) & $0^{\mathrm{a}}$ & $12.7^{\mathrm{b}}$ & $16.7^{\mathrm{b}}$ \\
\hline Alcoholism (\%) & 16.7 & 0 & 13.3 \\
\hline Goiter (palpation) $(\%)$ & 50.0 & 37.5 & 16.7 \\
\hline Systolic arterial ${ }^{1}$ pressure $(\mathrm{mmHg})$ & $137 \pm 28.2$ & $130 \pm 20$ & $140 \pm 14$ \\
\hline Diastolic arterial pressure $(\mathrm{mmHg})$ & $84 \pm 15.1$ & $83 \pm 11$ & $88 \pm 14$ \\
\hline
\end{tabular}




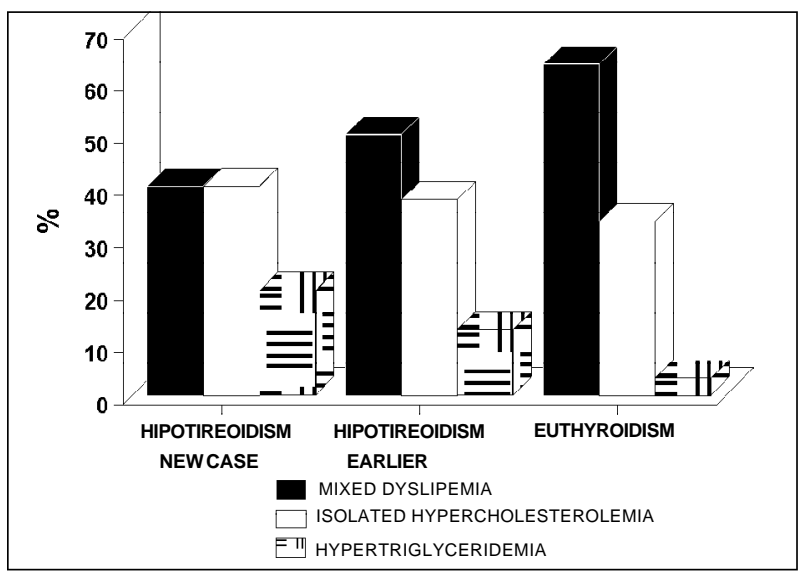

Fig. 1 - Hyperlipemia types of 51 patients (\%), hyperlipemic according to thyroid function (hypothyroidism - new cases, earlier cases, and euthyroid).

\begin{tabular}{|c|c|c|c|}
\hline \multicolumn{4}{|c|}{$\begin{array}{l}\text { Table II - Laboratory blood characteristics (average } \pm \text { SD) of } \\
\text { hyperlipemic patients, according to their thyroid function }\end{array}$} \\
\hline & \multicolumn{2}{|l|}{ Hypothyroidism } & \multirow{2}{*}{$\begin{array}{l}\text { Euthyroidism } \\
\qquad(\mathrm{n}=30)\end{array}$} \\
\hline & New case $(n=5)$ & Earlier $(\mathrm{n}=16)$ & \\
\hline $\mathrm{CT}(\mathrm{mg} \%)$ & $269,4 \pm 62,1$ & $255,7 \pm 54,0$ & $266,7 \pm 55,8$ \\
\hline HDL (mg\%) & $44,2 \pm 10,3^{\mathrm{a}}$ & $32,8 \pm 9,0^{\mathrm{b}}$ & $30,2 \pm 8,3^{\mathrm{b}}$ \\
\hline LDL (mg\%) & $179,6 \pm 67,3$ & $177,7 \pm 45,3$ & $199,4 \pm 47,0$ \\
\hline $\mathrm{TG}(\mathrm{mg} \%)$ & $196,0 \pm 128,5$ & $249,1 \pm 158,3$ & $260,6 \pm 138,9$ \\
\hline Glycemia (mg\%) & $97,6 \pm 11,5$ & $99,1 \pm 12,3$ & $99,7 \pm 12,1$ \\
\hline T4 livre (ng/dL) & $0,98 \pm 0,5^{\mathrm{a}}$ & $1,38 \pm 0,59^{b}$ & $1,40 \pm 0,27^{\mathrm{b}}$ \\
\hline $\mathrm{TSH}^{1}(\mu \mathrm{IU} / \mathrm{mL})$ & $9,2(3-48)^{\mathrm{a}}$ & $2,6(0,02-22)^{\mathrm{b}}$ & $1,4(0,4-3,5)^{\mathrm{b}}$ \\
\hline Creatinine $(\mathrm{mg} \%)$ & $0,89 \pm 0,20$ & $0,97 \pm 0,21$ & $1,02 \pm 0,28$ \\
\hline
\end{tabular}

neral can be potentially beneficial and financially viable, especially in women over $50^{10,12,13}$ or 35 years according to other authors ${ }^{13}$. Considering the frequency of hypothyroidism reported for samples of hyperlipemic subjects and the deleterious effects of these alterations on the lipid profile and the cardiovascular system, the results obtained suggest that the tracking of thyroid changes would also be potentially beneficial to this group of patients ${ }^{4-6,12}$.

Some authors have reported that only patients having a cholesterolemia higher than $300 \mathrm{mg} / \mathrm{dL}$ should be tested for hypothyroidism in view of the higher frequency of subclinical hypothyroidism (SCH) among them ${ }^{14,15}$. Corroborating the results of others ${ }^{5,13,15}$, our findings showed that serum cholesterol concentrations in recent or earlier diagnosed cases of hypothyroidism were on average smaller than those described by those authors and were not correlated with thyroid function ${ }^{13}$.

The types of hyperlipemia most frequently encountered in our hypothyroid patients were isolated hypercho- lesterolemia and mixed hyperlipemia, similar to those described by other authors ${ }^{8}$.

A majority of studies ${ }^{3,4,6,16}$ show average serum concentration of HDL higher than $40 \mathrm{mg} / \mathrm{dL}$ in subclinical or clinical hypothyroidism, similar, therefore, to the new cases of the disease in the present sample. We verified that serum concentrations of HDL-cholesterol were significantly lower among previously reported hypothyroid and euthyroid cases, in relation to new cases of hypothyroidism. This difference may be explained in part by the higher frequency of smoking in the first 2 groups, a factor exerting a negative influence on HDL-cholesterol blood concentration ${ }^{8}$.

The effect of the replenishment of thyroid hormone on the lipemia of $\mathrm{SCH}$ patients is controversial ${ }^{5,6}$, but its beneficial effect in clinical (low total or free T4, high TSH), hypothyroidism patients has been reported ${ }^{14,16}$.

We observed that patients with an earlier diagnosis of hypothyroidism, even if receiving thyroxin treatment, had hyperlipemia, in part due to insufficient treatment of their hypothyroidism or a genetic predisposition towards hyperlipemia ${ }^{17}$ or both. These patients could potentially benefit from the association of thyroxin replacement ${ }^{8}$ with hygienic-dietary-hypolipemic drugs measures.

Dieckman et al ${ }^{4}$ verified that the decrease in serum concentration of total and LDL-cholesterol in SCH following thyroid hormone treatment occurred in patients with levels of TSH $>10 \mathrm{Um} / \mathrm{L}$. Due to the small number of patients in our sample, it was not possible to evaluate therapeutic results with thyroxin in our $\mathrm{SCH}$ group of patients.

One of the mechanisms of action of thyroid hormones on lipid metabolism is their effect on genes associated with hepatic receptors of LDL-cholesterol ${ }^{17}$. The variability of the lipid profile and of the response of lipemia to the replacement of these hormones in hypothyroidism is partially related to the variation in the expression of this gene ${ }^{4,17}$.

Because hypothyroidism is one of the secondary causes of hyperlipemia ${ }^{8}$, it is associated to with cardiovascular risk factors ${ }^{2,3}$, and it is capable of aggravating pre-existing lipid dysfunction ${ }^{3,9}$, it is potentially possible to normalize lipemia with a specific treatment of thyroxin replacement ${ }^{4,14,16}$, we suggest, therefore, that hyperlipemic patients, in particular those at risk of thyropathy (women over 55 years of age, carriers of IRC, diabetics, and persons coming from endemically iodine-deprived areas) should be screened for hypothyroidism, corroborating recommendations of other authors ${ }^{3-6}$.

\section{Acknowledgement}

To Prof. Dr. Álvaro Oscar Campana, for the collaboration rendered. 


\section{References}

1. Larsen PR, Davies TF, Hay ID. The thyroid gland. In: Wilson JD, Foster DW, Kronemberg HM, Larsen PR. Eds. Williams Textbook of Endocrinology, $9^{\text {th }}$ ed. Philadelphia: WB Saunders Company 1998; 389-516: 1819.

2. Gomberg-Maitland M, Frishman WH. Thyroid hormone and cardiovascular disease. Am Heart J 1998; 135: 187-96.

3. Michalopoulou G, Alevizaki M, Piperingos G, et al. High serum cholesterol levels in persons with 'high-normal' TSH levels: should one extend the definition of subclinical hypothyroidism? Eur J Endocrinol 1998; 138: 141-5.

4. Diekman T, Lansberg PJ, Kastelein JJP, Wiersinga WM. Prevalence and correction of hypothyroidism in a large cohort of patients referred for dyslipidemia. Arch Intern Med 1995; 155: 1490-5.

5. Helfand M, Redfern CC. Screening for thyroid disease: an update. Ann Intern Med 1998; 129: 144-58.

6. Tsimihodimos V, Bairaktari E, Tzallas C, Miltiadus G, Liberopoulos E, Elisaf M The incidence of thyroid function abnormalities in patients attending an outpatient lipid clinic. Thyroid 1999; 9: 365-8.

7. Gomés F, Cueva RDL, Wauters JP, Béraud TL. Endocrine abnormalities in patients undergoing long term hemodialysis. Am J Med 1980; 68: 522-30.

8. Quintão ECR. Hiperlipidemias: etiologia. In: Quintão ECR (ed) - Colesterol e Aterosclerose. Rio de Janeiro: Qualitymark, 1992: 71-123.

9. Pimenta WP, Mazeto GMFS, Demarco FVC, et al. Prevalência de tireopatias em uma população de diabéticos. Arq Bras Endocrinol Metab 1997; 41: 31-4.
10. Wang C, Crapo LM. The epidemiology of thyroid disease and implications for screening. Endocrinol Metab Clin North Am 1997; 26: 189-218.

11. DeGroot LJ, Mayor G. Admission screening by thyroid function tests in an acute general care teaching hospital. Am J Med 1992; 93: 558-64.

12. Wiersinga WM. Subclinical hypothyroidism and hyperthyroidism. I - Prevalence and clinical relevance. Neth J Med 1995; 46: 197-204.

13. Danese MD, Powe NR, Sawin CT, Landenson PW. Screening for mild thyroid failure at the periodic health examination: a decision and cost - effectiveness analysis. JAMA 1996; 276: 285-92.

14. Tanis BC, Westendorp RGJ, Smelt AHM. Effect of thyroid substitution on hypercholesterolaemia in patients with subclinical hypothyroidism: a reanalysis of intervention studies. Clin Endocrinol 1996; 44: 643-9.

15. Oettgen P, Ginsburg GS, Horowitz GL, Pasternak RC. Frequency of hypothyroidism in adults with serum total cholesterol levels $>200 \mathrm{mg} / \mathrm{dl}$. Am J Cardiol 1994; 73: 955-7.

16. Olukoga AO, Crowley VEF, Lawal A, Weinkove C. Hyperlipidaemia and hypothyroidism: Screening patients for hypothyroidism before treatment. Br Med J 1994; 308: 918.

17. Wiseman SA, Powel JT, Humphries SE, Press M. The magnitude of the hypercholesterolemia of hypothyroidism is associated with variation in the low density lipoprotein receptor gene. J Clin Endocrinol Metab 1993; 77: 108-12. 